\title{
Simulations on arrangements of induced jet-fans as auxiliary ventilation for a mechanical ventilated space with openings
}

\author{
Wenxuan Zhao ${ }^{1}$, Wei $\mathrm{Ye}^{1,2, *}$, Qianru Zhang ${ }^{1}$, and $X u$ Zhang $^{1}$ \\ ${ }^{1}$ School of Mechanical Engineering, Tongji University, Shanghai 200092, China \\ ${ }^{2}$ Key Laboratory of Performance Evolution and Control for Engineering Structures of Ministry of Education, Tongji University, \\ Shanghai 200092, China
}

\begin{abstract}
Underground garages, indoor stadiums, or more commonly used seagoing ships, can be used as large multi-purpose spaces, which are suitable for the carriage of a wide range of cargoes, as well as evacuation of people at overseas. The indoor environment in a multi-purpose cabin usually varies, in terms of pollutant emissions, hazardous levels and the corresponding ventilation requirements. A possible solution, in addition to a single regular HVAC system, is to use multiple induced jet fans. However, to pre-determine a universal design of fans, e.g., numbers, locations, directions, angles and flowrates, etc., may not be practical. In this preliminary work, methods to design the auxiliary ventilation system were discussed. The heat sources are located in the four corners on the floor. CFD method is used to further study the effects of six regular and four irregular arrangements of a $2 \times 2$ array of fans on local heat dilution with or without natural ventilation (e.g., additional openings in the space). Heat exhaust efficiency is used to evaluate the effects of different arrangements of fans on local heat dilution. The results show that adjustable ventilation using induced fans would be useful to provide various airflow distribution for a large space and the dilution of the heat can be improved and the areas of high temperature inside the space can be reduced. Furthermore, the heat exhaust efficiency would be higher and the induced fans have a more significant effect, especially when additional natural ventilation is available.
\end{abstract}

\section{Introduction}

Underground garages, indoor stadiums, or more commonly used seagoing ships, can be used as large multi-purpose spaces ${ }^{[1-4]}$, which are usually built for the carriage of a wide range of cargoes (e.g., woods, materials and other relative smaller vehicles, etc.), as well as evacuation of people at overseas. Two related characteristics of a multi-purpose space are as follows ${ }^{[5-}$ 8]: first, the indoor environment usually varies, in terms of heat-releasing sources, pollutant emissions, hazardous levels and so on. Second, the corresponding ventilation requirements also vary, depending on the targeted environment. To be more specific, ventilation requirements would be relatively low for uninflammable goods, but can be high for volatile or hazardous gases, or high density of occupants. Thus, to provide, maintain or readjust the indoor environment under various conditions using a single fixed HVAC system can be difficult.

A possible solution to provide adequate ventilation and appropriate airflow pattern is to use multiple induced jet fans ${ }^{[9-11]}$. However, to pre-determine a universal design of the fan arrangements, e.g., numbers, locations, directions angles, and flow-rates, etc., may not be practical. Although overall dilution could be the most general goal for ventilation, other strategies, such as air curtain, air spilt or airflow short circuit, etc., are also common in accordance to the physical and chemical characteristics of the emissions, and/or the required airflow rate for occupants. At present, methods to design an auxiliary ventilation system using induced jet fans to achieve multiple purposes in a large space are still not clear.

\section{Methods}

\subsection{Overall approach}

In our previous work, the effects of a $2 \times 2$ array of fans on achieving four different purposes (i.e., dilution, air spilt or short-circuit airflow) were studied [12,13]. A reduced-scale experimental set-up for pollution control while using induced jet fans was employed to study the effects of an array of fans, and also to validate the numerical (CFD) method [14,15]. In this paper, CFD method is used to further study the effects of the arrangements of fans on local heat dilution while incorporating natural ventilation.

\subsection{CFD methods}

A simplified space with additional openings is used to study the auxiliary ventilation using induced jet fans, as shown in Fig. 1(a), with geometric dimensions shown in Fig. 1(b). Assuming the heat sources are located in the four corners on the floor and openings are located on the surrounding walls. The detailed CFD methods are as

\footnotetext{
* Corresponding author: weiye@tongji.edu.cn
} 
follows, e.g., meshing (1.4 million cells; with independence check), turbulence model (realizable k- $\varepsilon$, standard wall function), Boussinesq approximation, boundary conditions (as shown in Table 1), SIMPLE scheme and discretion method (PRESTO! for pressure, second order upwind method for momentum, turbulent and energy terms), etc., that are kept as identical as possible when performing for various cases using the same commercial CFD code.

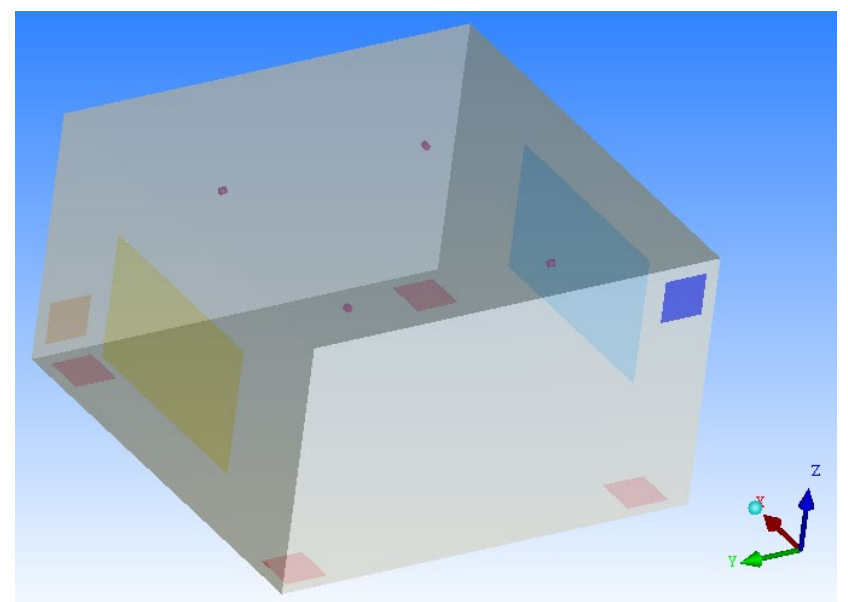

(a) CFD model used to study jet fan effects

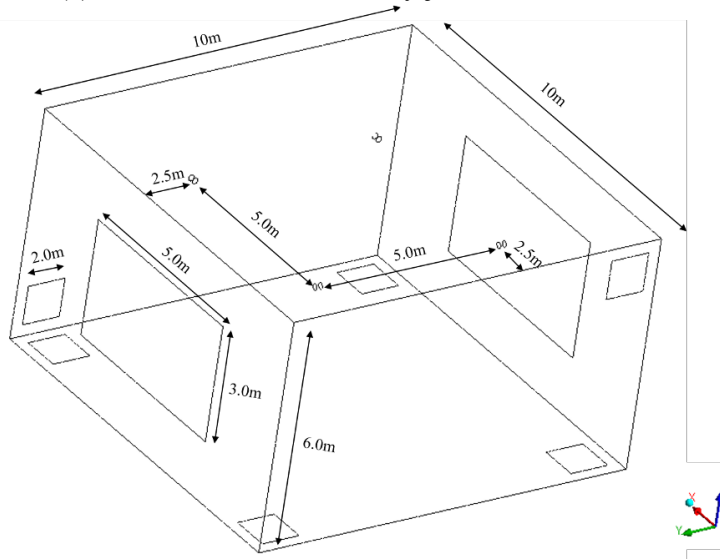

(b) Geometric dimensions of CFD model

Fig. 1. CFD model and geometric dimensions

Table 1. Cell zone and boundary conditions

\begin{tabular}{|c|c|c|}
\hline Zones / boundaries & Type & Settings \\
\hline $\begin{array}{l}\text { Outlet of the } \\
\text { induced jet fans }\end{array}$ & & $\begin{array}{l}\text { Velocity is } 10 \mathrm{~m} / \mathrm{s} \text { and } \\
\text { normal direction is } 20^{\circ} \\
\text { inclined to the ground }\end{array}$ \\
\hline $\begin{array}{l}\text { Air supply of } \\
\text { mechanical } \\
\text { ventilation }\end{array}$ & $\begin{array}{l}\text { Velocity- } \\
\text { inlet }\end{array}$ & $\begin{array}{c}\text { Temperature is } 18^{\circ} \mathrm{C} \text { and } \\
\text { velocity is } 1 \mathrm{~m} / \mathrm{s} \text {, equivalent } \\
\text { to } 6 \mathrm{~h}^{-1}\end{array}$ \\
\hline $\begin{array}{l}\text { Air exhaust of } \\
\text { mechanical } \\
\text { ventilation }\end{array}$ & $\begin{array}{l}\text { Pressure- } \\
\text { outlet }\end{array}$ & \\
\hline $\begin{array}{c}\text { Air inlet of natural } \\
\text { ventilation }\end{array}$ & $\begin{array}{l}\text { Pressure- } \\
\text { inlet }\end{array}$ & \multirow{2}{*}{$\begin{array}{l}\text { Temperature of outdoor air is } \\
18^{\circ} \mathrm{C} \text {, equal to the } \\
\text { temperature of air supply of } \\
\text { mechanical ventilation }\end{array}$} \\
\hline $\begin{array}{c}\text { Air outlet of natural } \\
\text { ventilation }\end{array}$ & $\begin{array}{c}\text { Pressure- } \\
\text { outlet }\end{array}$ & \\
\hline Heat sources & Wall & $\begin{array}{l}\text { The second type boundary } \\
\text { condition as a constant heat } \\
\text { flux of } 1000 \mathrm{~W} / \mathrm{m}^{2}\end{array}$ \\
\hline Remaining surfaces & Wall & Adiabatic boundary condition \\
\hline
\end{tabular}

\subsection{Assessment methods}

Average temperatures of air at the exhaust outlet and in the whole space are used to evaluate the effects of fan arrangements. In addition, the heat exhaust efficiency is also employed, as shown in Eq. (1).

$$
\eta_{t}=\frac{t_{e}-t_{s}}{t_{a}-t_{s}}
$$

Where $t_{\mathrm{e}}$ is average temperature of air at the exhaust outlet, $t_{\mathrm{a}}$ is average temperature of air in the whole space and $t_{\mathrm{s}}$ is temperature of air supply.

\section{Results and discussions}

\subsection{The effects of induced jet fan arrangements on temperature control without natural ventilation}

Seven cases are first dedicated to study the effects of arrangements on heat control on the condition of mechanical ventilation without natural ventilation. Among the cases, as shown in Fig. 2, case 0 has no running jet fans, while the rest are "regular" arrangements, i.e., clockwise, counter-clockwise, upward, downward, leftward and rightward, respectively.

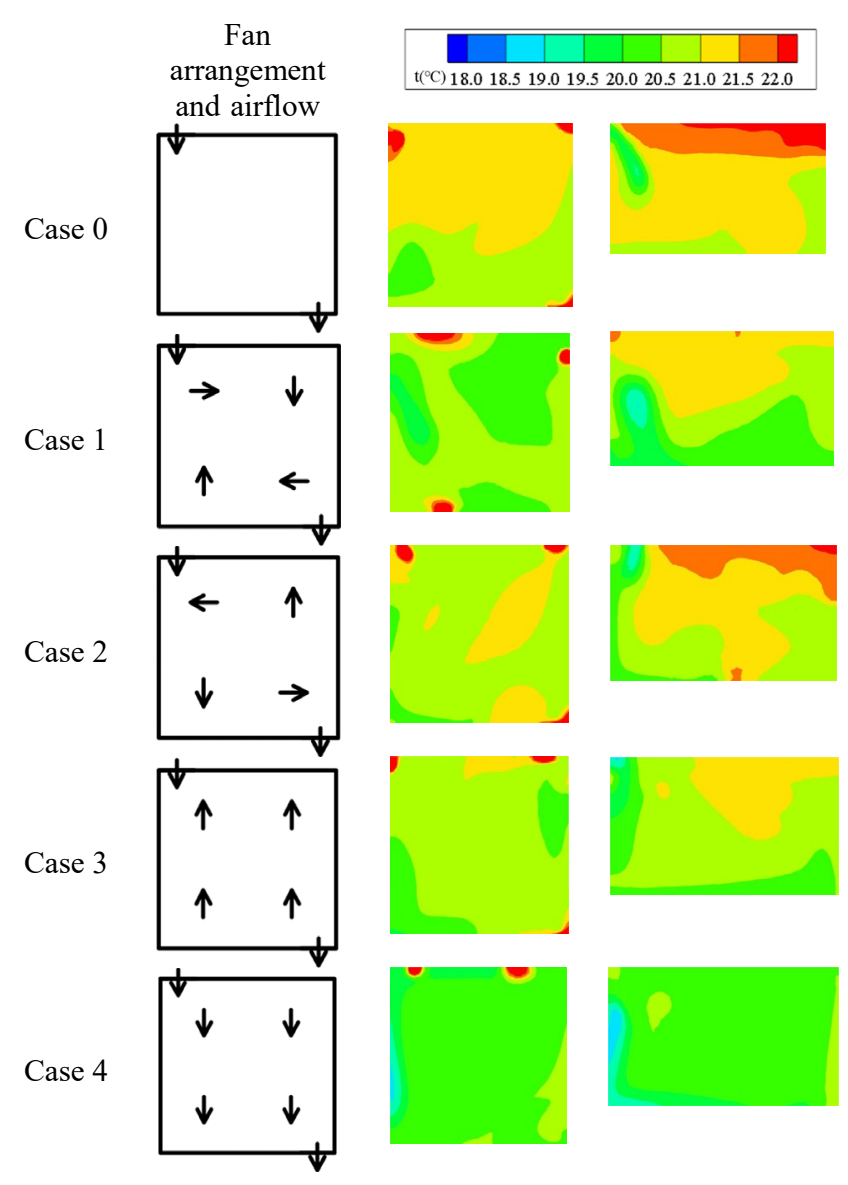




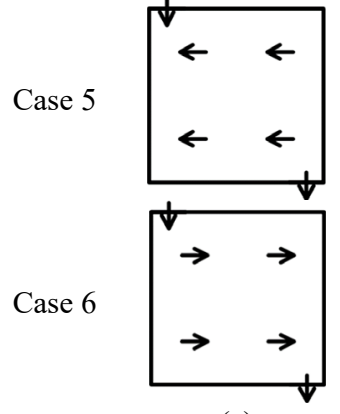

(a)

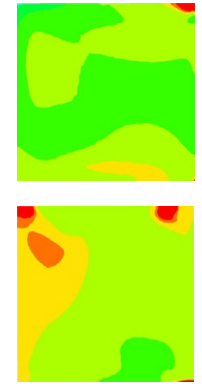

(b)
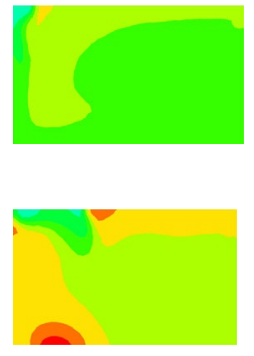

(c)

(a) Case design and air flow

(b) Temperature at $1.5 \mathrm{~m}$ in height

(c) Temperature at central cross-section

Fig. 2. Comparison of "regular" arrangements of induced jet fans on heat control without natural ventilation

Another four cases that are designed to represent "irregular" arrangements of the induced fans are also used to study the effects on heat control. Since there are hundreds of irregular arrangements can be made, only four are selected to demonstrate and are shown in Fig. 3.

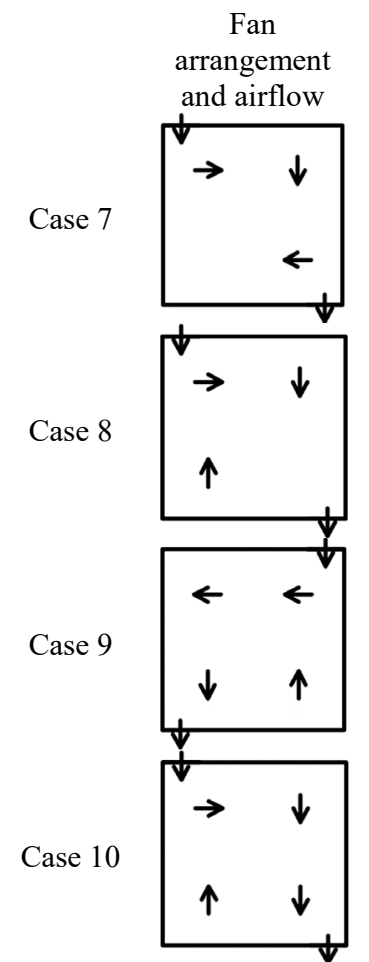

(a)
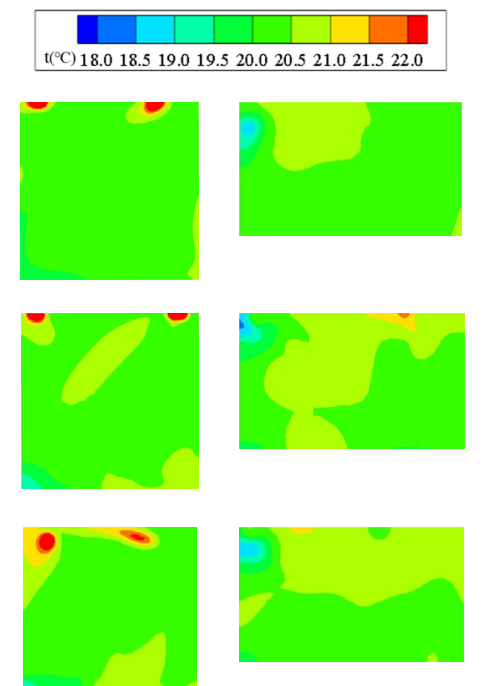

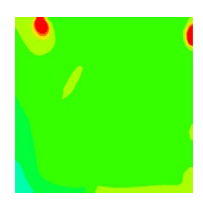

(b)

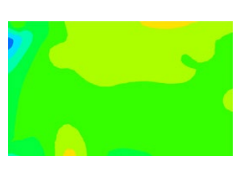

(c)

(a) Case design and air flow

(b) Temperature at $1.5 \mathrm{~m}$ in height

(c) Temperature at central cross-section

Fig. 3. Comparison of "irregular" arrangements of induced jet fans on heat control without natural ventilation

Based on Figs. 2 and 3, it can be found that, without the induced fans, the heat can be accumulated in the areas that near the heat sources. In other words, by using the induced fans, the dilution of the heat can be improved and the areas of high temperature inside the space can be reduced. This is because the air supply and air return of this space can act in a way that the air movement in the central areas can be low, however, under the action of the induced fans, the intensity of air flow and heat transfer exchange in the space are enhanced to accelerate heat removal. In addition, different arrangement of the induced fans would lead to different temperature distributions.

Furthermore, heat exhaust efficiency is used to evaluate the effects of different arrangements of fans on local heat dilution without natural ventilation, as shown in Table 2. It needs to be noticed that the heat exhaust efficiency is mainly limited by air change rate of the space. In other words, the induced fans may not be able to increase or decrease the heat exhaust efficiency to a great extent. And one of the main effects of using these induced fans is to eliminate areas that have potential high concentrations of heat. In this sense, cases 4 and 5 are showing better results in terms of averaging the concentrations and heat removal.

Table 2. Heat exhaust efficiency of "regular" and "irregular" arrangements of the induced fans without natural ventilation

\begin{tabular}{|c|c|c|c|}
\hline & $\begin{array}{c}\text { Average } \\
\text { temperature of air } \\
\text { exhaust vent }\left({ }^{\circ} \mathrm{C}\right)\end{array}$ & $\begin{array}{c}\text { Average } \\
\text { temperature of } \\
\text { air in space }\left({ }^{\circ} \mathrm{C}\right)\end{array}$ & $\begin{array}{c}\text { Heat } \\
\text { exhaust } \\
\text { efficiency }\end{array}$ \\
\hline Case 0 & 21.3 & 21.1 & 1.07 \\
\hline Case 1 & 21.3 & 20.8 & 1.17 \\
\hline Case 2 & 21.3 & 21.1 & 1.09 \\
\hline Case 3 & 21.3 & 20.8 & 1.17 \\
\hline Case 4 & 21.3 & 20.4 & 1.40 \\
\hline Case 5 & 21.7 & 20.4 & 1.53 \\
\hline Case 6 & 21.4 & 20.9 & 1.17 \\
\hline Case 7 & 21.3 & 20.4 & 1.34 \\
\hline Case 8 & 21.2 & 20.5 & 1.30 \\
\hline Case 9 & 21.3 & 20.5 & 1.33 \\
\hline Case 10 & 21.2 & 20.4 & 1.37 \\
\hline
\end{tabular}

\subsection{The effects of induced jet fan arrangements on temperature control with natural ventilation}

Similar to Section 3.1, eleven cases with additional natural ventilation (by utilizing the large opening as air inlets and outlets) are designed to study the effects of arrangements of jet fans on heat control, as comparisons to those of mechanical ventilation. The outside temperature is set to be $18^{\circ} \mathrm{C}$ (which is equal to temperature of air supply of mechanical ventilation), as summarized in Table 1. Temperature distributions and heat exhaust efficiencies of "regular" and "irregular" arrangements of the induced fans with natural ventilation are shown in Fig. 4 and Table 3.

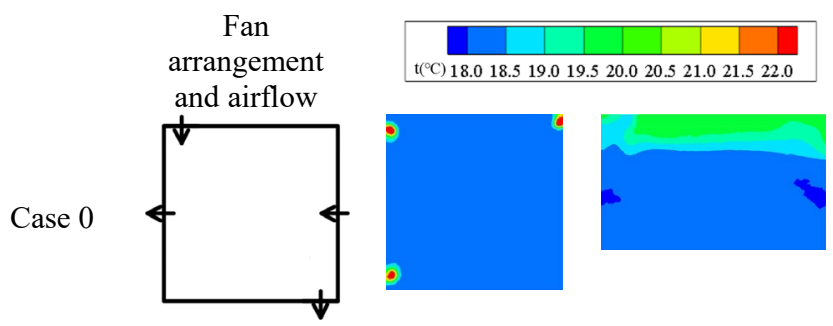




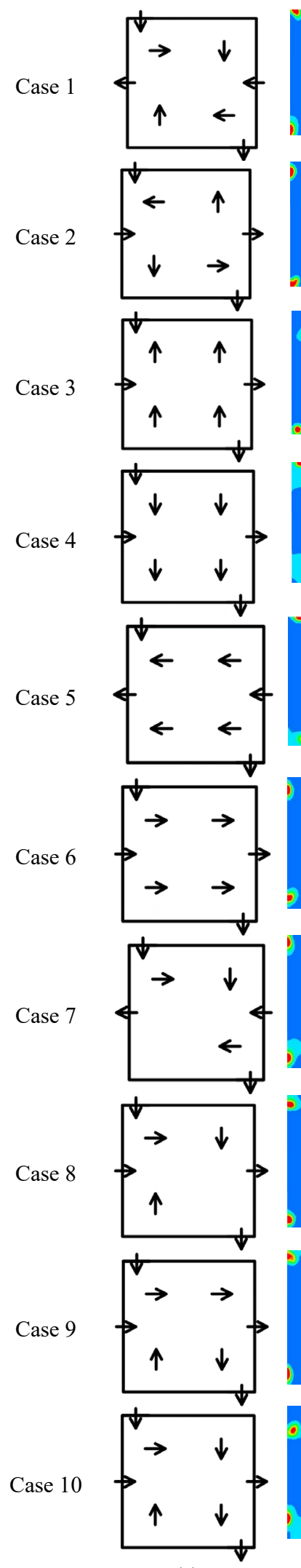

(a)
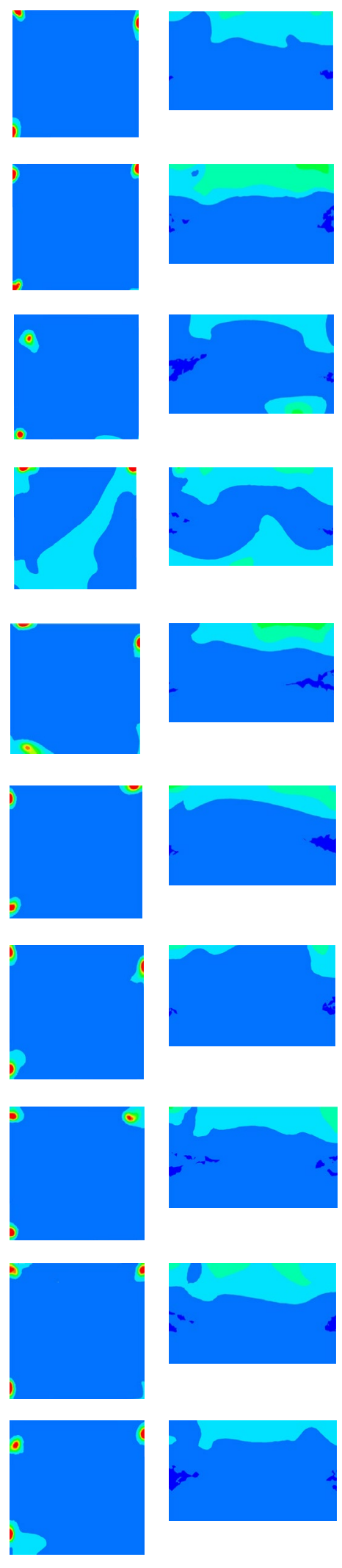

(b)

(c)

(a) Case design and air flow

(b) Temperature at $1.5 \mathrm{~m}$ in height

(c) Temperature at central cross-section

Fig. 4. Comparison of "regular" and "irregular" arrangements of induced jet fans on heat control with natural ventilation
It can be found that the temperature in the space is lower when incorporating natural ventilation. When changing the directions of the four induced fans, the air that enters or leaves the room through the two openings varies, which is affected by jet-fan flows. Therefore, the adjustable ventilation using induced fans would be useful to increase the heat exhaust efficiency and provide a better airflow environment for the space.

Table 3. Heat exhaust efficiency of "regular" and "irregular" arrangements of the induced fans with natural ventilation

\begin{tabular}{|c|c|c|c|}
\hline & $\begin{array}{c}\text { Average } \\
\text { temperature of air } \\
\text { exhaust vent }\left({ }^{\circ} \mathrm{C}\right)\end{array}$ & $\begin{array}{c}\text { Average } \\
\text { temperature of } \\
\text { air in space }\left({ }^{\circ} \mathrm{C}\right)\end{array}$ & $\begin{array}{c}\text { Heat } \\
\text { exhaust } \\
\text { efficiency }\end{array}$ \\
\hline Case 0 & 18.7 & 18.5 & 1.31 \\
\hline Case 1 & 18.8 & 18.4 & 2.15 \\
\hline Case 2 & 18.8 & 18.5 & 1.63 \\
\hline Case 3 & 19.3 & 18.8 & 1.69 \\
\hline Case 4 & 19.0 & 18.6 & 1.74 \\
\hline Case 5 & 19.0 & 18.4 & 2.44 \\
\hline Case 6 & 18.7 & 18.4 & 2.00 \\
\hline Case 7 & 18.8 & 18.4 & 2.06 \\
\hline Case 8 & 18.9 & 18.4 & 2.12 \\
\hline Case 9 & 18.9 & 18.4 & 2.08 \\
\hline Case 10 & 18.8 & 18.4 & 2.04 \\
\hline
\end{tabular}

In addition to Table 3, Fig. 5 summarizes heat exhaust efficiencies of "regular" and "irregular" arrangements of the induced fans with or without additional openings (natural ventilation). The results show that, first, the heat exhaust efficiency would be higher with natural ventilation. Second, the induced fans can be used to increase the heat exhaust efficiency under natural ventilation. Third, various fan arrangements can result in different heat exhaust efficiencies. In this study, cases 1 and 5 show higher potential of heat removing.

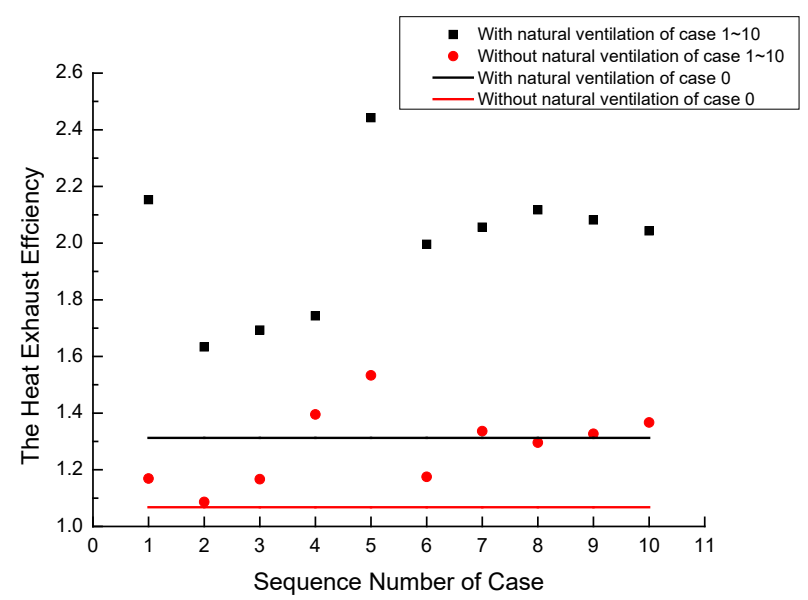

Fig. 5. Comparison of the heat exhaust efficiency of "regular" and "irregular" arrangements of induced jet fans on heat control whether there is natural ventilation

\section{Conclusions and limitations}

\subsection{Conclusions}


Preliminary discussions on effects of the induced fans in a large space on heat control with or without additional openings (i.e., natural ventilation) are presented. Six "regular" and four "irregular" arrangements of an array of $2 \times 2$ fans are studied using CFD simulations.

Major conclusions are as follows:

(1) Adjustable ventilation using induced fans would be useful to provide various airflow environment within a space, especially when the required ventilation strategies would be varied significantly under different circumstances.

(2) By using the induced fans, the dilution of the heat can be improved and the areas of high temperature can be reduced with or without additional openings.

(3) The heat exhaust efficiency can be improved using the induced fans, especially when incorporating natural ventilation (e.g., additional openings are available in the space or room such as garages).

\subsection{Limitations}

Location of heat sources, fluctuations of outdoor wind velocity and direction, may all be the important factors affecting temperature environment and heat exhaust efficiency in the space. More studies are needed to further understand the design method of induced fans (in arrays) for multi-purpose spaces, and also the possibilities of using induced fans in a multi-array fashion.

\section{Acknowledgment}

This research has been supported by National Natural Science Foundation of China through Grant No. 51878463.

\section{References}

1. H. Wang, X. Tang, C. Huang. Investigating ventilation system performance in large space building: A nozzle primary air supply with secondary airflow-relay system. Sci. Technol. Built Environ., 23, 296-306 (2017)

2. X. Shao, X. Li. Evaluating the potential of airflow patterns to maintain a non-uniform indoor environment. Renew. Energy, 73, 99-108 (2015)

3. X. Ma, X. Shao, X. Li, Y. Lin. An analytical expression for transient distribution of passive contaminant under steady flow field. Build. Environ, 52, 98-106 (2012)

4. S. Murakami. New scale for ventilation efficiency and their application based on numerical simulation of room airflow. Proceedings of International Symposium on Room Air Convection and Ventilation Effectiveness. Tokyo, Japan: University of Tokyo, 22-38 (1992)

5. X. Ye, Y. Kang, B. Zuo, K. Zhong. Study of factors affecting warm air spreading distance in impinging jet ventilation rooms using multiple regression analysis. Build. Environ, 120, 1-12 (2017)
6. R. Kosonen, N. Lastovets, P. Mustakallio, G.C. da Graça, N.M. Mateus, M. Rosenqvist. The effect of typical buoyant flow elements and heat load combinations on room air temperature profile with displacement ventilation. Build. Environ, 108, 207219 (2016)

7. Y. Chen, B. Raphael, S.C. Sekhar. Experimental and simulated energy performance of a personalized ventilation system with individual airflow control in a hot and humid climate. Build. Environ, 96, 283292 (2016)

8. Y. Cheng, Z. Lin. Experimental study of airflow characteristics of stratum ventilation in a multioccupant room with comparison to mixing ventilation and displacement ventilation. Indoor Air, 25, 662-671 (2015)

9. X. Cao, J. Li, J. Liu, W. Yang. 2D-PIV measurement of isothermal air jets from a multi-slot diffuser in aircraft cabin environment. Build. Environ, 99, 44-58 (2016)

10. A. Abdel-Fattah. Numerical and experimental study of turbulent impinging twin-jet flow. Exp. Therm. Fluid Sci., 31, 1061-1072 (2007)

11. M. Chen, R. Chalupa, A.C. West, V. Modi. High schmidt mass transfer in a laminar impinging slot jet flow. Int. J. Heat Mass Transf., 43, 3907-3915 (2000)

12. S.J. Wang, X. Zhang, W. Ye. Simulation of using inducing fan to eliminate potential ventilation dead corners with different hazardous gas emissions. Build. Energy \& Environ, 35, 8-11 (2016) . In Chinese.

13. S.J. Wang, X. Zhang, W. Ye. Numerical simulation of using inducing fan to eliminate potential ventilation dead corners of hazardous gas. Archit. Technol. 47, 14-16 (2016). In Chinese.

14. S.J. Wang. Optimization of multi-directional contaminated airflow control technology in a narrow space. Master's Dissertation. Shanghai: Tongji University (2017) . In Chinese.

15. W. Ye, Q. Zhang, S.J. Wang, X. Zhang. Exposure modular and adjustable ventilation using induced jet fans for a multi-purpose large space. Electronical Proceedings of the $15^{\text {th }}$ International Indoor Air Quality and Climate, Philadelphia, PA, USA (2018.07. ID105) 